
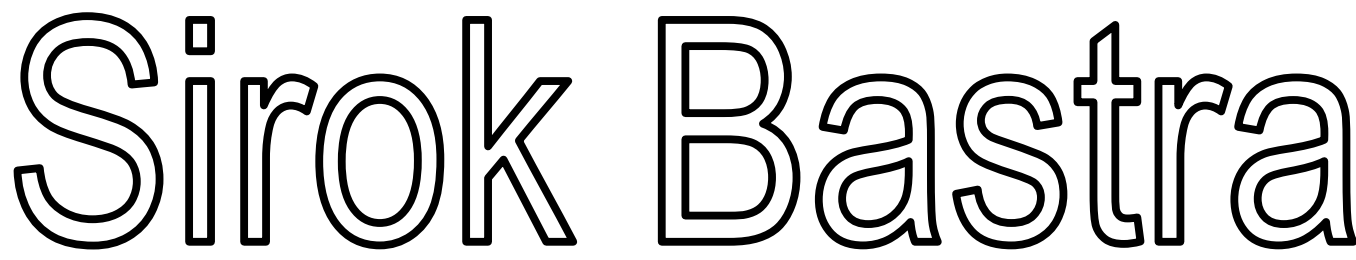

JURNAL ILMIAH KEBAHASAAN DAN KESASTRAAN

\begin{tabular}{|c|l|l|l|c|c|}
\hline $\begin{array}{c}\text { Sirok Bastra } \\
\text { Jurnal Kebahasaan dan } \\
\text { Kesastraan }\end{array}$ & Volume 4 & Nomor 2 & $\begin{array}{c}\text { Hlm. } \\
101-192\end{array}$ & $\begin{array}{c}\text { Pangkalpinang, } \\
\text { Desember } \\
2016\end{array}$ & $\begin{array}{c}\text { ISSN } \\
2354-7200\end{array}$ \\
\hline
\end{tabular}

KANTOR BAHASA KEPULAUAN BANGKA BELITUNG 

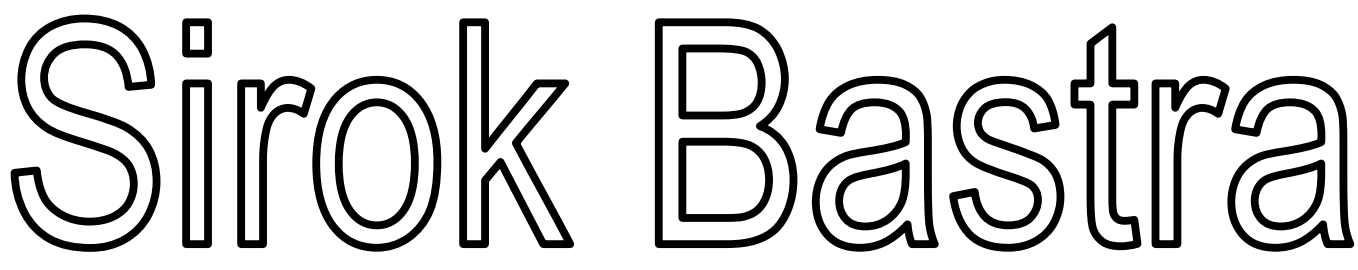

\title{
JURNAL ILMIAH KEBAHASAAN DAN KESASTRAAN
}

Jurnal ini merupakan wadah informasi kebahasan, kesastraan, dan pengajarannya yang memuat hasil penelitian, studi kepustakaan, dan tulisan ilmiah bidang kebahasan dan kesastraan serta pengajarannya. Sirok Bastra terbit dua kali setahun, yakni Juni dan Desember, serta terbit sejak Juni 2013.

\section{Penanggung Jawab}

Kepala Kantor Bahasa Kepulauan Bangka Belitung

Drs. Hidayatul Astar, M.Hum.

\section{Mitra Bestari}

Prof. Dr. Agus Nuryatin, M.Hum. (Bidang Sastra dan Pengajarannya)

Prof. Amrin Saragih, Ph.D., M.A. (Bidang Bahasa dan Pengajarannya)

Dr. Felicia Nuradi Utorodewo, M.Hum. (Bidang Bahasa dan Pengajarannya)

Dr. Pujiharto, M.Hum. (Bidang Sastra dan Pengajarannya)

\author{
Pemimpin Redaksi \\ Rahmat Muhidin, S.S. \\ Penyunting \\ Dr. Asyraf Suryadin, M.Pd. \\ Sarman, S.Pd, \\ Prima Hariyanto, S.Hum. \\ Perancang Sampul \\ Feri Pristiawan, S.S. \\ Pengatak
}

Dewi Septi Kurniawati, S.Kom.

\begin{abstract}
Alamat Redaksi dan Penerbit
Kantor Bahasa Kepulauan Bangka Belitung

Jalan Letkol Saleh Ode 412, Kota Pangkalpinang, Prov. Kepulauan Bangka Belitung
\end{abstract}

Telepon (0717) 438455, Faksimile (0717) 9103317, Pos-el: sirokbastra@gmail.com, sirokbastra@kemdikbud.go.id

Pemuatan suatu tulisan dalam jurnal ini tidak berarti redaksi menyetujui isi tulisan tersebut. Isi tulisan menjadi tanggung jawab penulis. Tulisan telah ditinjau dan diulas oleh mitra bestari. Setiap karangan dalam jurnal ini dapat diperbanyak setelah mendapat izin tertulis dari penulis, redaksi, dan penerbit. 


\section{PENGANTAR}

Puji syukur ke hadirat Pemilik dan Pencipta semesta ini yang memiliki kuasa atas diri-Nya sendiri. Dialah Tuhan Yang Maha Esa yang telah memberikan rahmat dan hidayah-Nya sehingga Volume 4 Nomor 2 Jurnal Sirok Bastra Tahun 2016 dapat terbit tepat pada waktunya.

Pada edisi ini, dimuat sepuluh tulisan, yakni enam tulisan kebahasaan dan empat tulisan kesastraan.

Dalam penelitiannya, Satwiko Budiono mengkaji penamaan warna masyarakat Betawi di Marunda, Jakarta Utara. Berdasarkan penelitian, masyarakat Betawi di Marunda memiliki penggolongan penyebutan warna berdasarkan sebelas kategori, yaitu buah, alat berat, minuman, makanan, anggota atau bagian tubuh, bagian mobil, warna, wajah, alam, tingkat kecerahan, dan tumbuhan. Selain itu, warna yang jarang ditemui hanya disebutkan berdasarkan tingkat kecerahan muda dan tua tanpa adanya asosiasi ke hal lainnya.

Dalam penelitiannya, Ayesa dan Miva Aziza membahas pengaruh aksen bahasa Jawa bunyi letup /d/ dalam bahasa Inggris. Berdasarkan penelitian, diketahui bahwa aksen bahasa Jawa memengaruhi durasi suatu ujaran, khususnya dalam pembunyian huruf letup /d/. Subjek penelitian ini adalah penutur asli bahasa Inggris dan penutur asing yang menguasai bahasa Inggris serta berbahasa ibu bahasa Jawa. Dari hasil temuan, terdapat perbedaan durasi antara penutur asli dan penutur asing yang menyebabkan perbedaan variasi bunyi letup $/ \mathrm{d} /$.

Dalam kajiannya, Nurul Masfufah mendeskripsikan bentuk dan makna peribahasa Dayak Benuaq. Berdasarkan hasil kajian, dapat diketahui bahwa masyarakat Dayak Benuaq sebagai penutur peribahasa tersebut tidak hanya sekadar mengungkapkan tuturan kosong, tetapi tuturan dalam peribahasa tersebut mencerminkan budaya, cara pandang, dan pola pikir masyarakat Dayak Benuaq dalam menjalani kehidupan.

Dalam kajiannya, Dwi Agus Erinita menganalisis ranah rasa yang dihasilkan oleh indra perasa dengan menggunakan pendekatan natural semantic metalinguage (NSM) yang dikembangkan oleh Anna Wierzbicka. Berdasarkan analisis, ranah rasa dalam bahasa Indonesia tidak hanya empat rasa pokok, yaitu manis, asam, asin, dan pahit, tetapi juga ada pedas, sepat, gurih, getir, hambar, dan tawar. Semua konsep rasa itu dapat dijelaskan melalui apa yang ada di alam dan kehidupan sehari-hari, seperti buah, bumbu, dan masakan.

Dalam kajiannya, Siti Hannah Sekarwati pelanggaran maksim sebagai strategi pengungkapan humor dalam video humor di akun Instagram Ria Yunita (@riaricis1795). Berdasarkan penelitian, diketahui bahwa daya ilokusi yang paling sering muncul adalah daya ilokusi direktif dan deklaratif. Penggunaan jenis daya ilokusi direktif dan deklaratif serta pelanggaran maksim yang ditemukan dalam data ini diasumsikan penulis sebagai strategi humor pada tindak tutur video di akun instagram Ria Ricis. Pelanggaran maksim yang ditemukan adalah pelanggaran maksim kualitas dan maksim relevansi.

Dalam tulisannya, Rissari Yayuk membahas tindak tutur perintah bujukan kepada anak-anak dalam bahasa Banjar. Berdasarkan hasil penelitian, tindak tutur perintah bujukan dalam bahasa Banjar memiliki penanda yu'yuk', ayu'ayo', kasi'cepat', lah 'lah', dan muhun'mohon'. Penggunaan strategi kesantunan berbahasa dalam tindak tutur ini meliputi strategi pujian, janji, menumbuhkan sikap optimistis, penanda solidaritas, dan melucu.

Dalam penelitiannya, Sarman mendeskripsikan nilai-nilai kearifan lokal masyarakat Belitung dalam cerita

Keramat Pinang Gading. Hasil kajian menunjukkan bahwa dari struktur relasi gender tidak ada peran yang dominan antara laki-laki dan perempuan. Sedangkan nilai kearifan lokal yang muncul dalam cerita ini adalah sikap jujur, bertanggung jawab, tolong-menolong, musyawarah, gotong- royong dan kerja sama.

Dalam kajiannya, Dede Hidayatullah membahas struktur, bentuk, dan fungsi mantra Dayak Abal. Dari hasil penelitian, mantra Abal yang ditemukan sebanyak sebelas mantra. Tujuh mantra menggunakan bahasa tunggal, tiga mantra menggunakan bahasa campuran, dan satu mantra menggunakan bahasa asing. Kesebelas mantra ini terdiri atas mantra yang berhubungan dengan kecantikan, cinta kasih, pengobatan, dan perisai diri. Kesebelas mantra yang ditemukan sangat dipengaruhi oleh agama Islam.

Dalam kajiannya, Dwi Oktarina mengkaji struktur fisik (unsur-unsur bunyi dan kata) dalam sajak "Perempuan-Perempuan Perkasa" karya Hartoyo Andangjaya. Hasil penelitian menunjukkan bahwa di dalam 
puisi ini terkandung unsur-unsur orkestrasi dan simbol bunyi, rima, diksi, denotasi dan konotasi, bahasa kiasan, pencitraan, gaya bahasa dan sarana retorika, serta faktor ketatabahasaan lainnya.

Dalam penelitiannya, Irawan Syahdi mengkaji arketipe-arketipe dalam cerita rakyat Batu Barayang yang berjudul "Legenda Siti Payung". Berdasarkan kajian yang dilakukan, ditemukan dua jenis arketipe, yaitu karakter dan simbol.

Kami mengucapkan terima kasih kepada para penulis yang telah bersedia menerbitkan karya mereka pada edisi ini. Para penulis merupakan peneliti, pakar, dosen, dan mahasiswa dari berbagai perguruan tinggi dan instansi. Terima kasih juga kami sampaikan kepada para mitra bestari kami yang telah memberi ulasan terhadap tulisan-tulisan yang masuk ke redaksi.

Demi memenuhi keberagaman isi dan penulis, Sirok Bastra membuka kesempatan bagi para peneliti dan penulis menyampaikan hasil penelitian dan pemikiran mutakhir dalam bidang kebahasaan, kesastraan, dan pengajarannya.

Pangkalpinang, Desember 2016

Tim Redaksi 


\section{UCAPAN TERIMA KASIH UNTUK MITRA BESTARI}

Redaksi Sirok Bastra mengucapkan terima kasih kepada para mitra bestari yang telah meninjau, menimbang, dan mengulas makalah-makalah yang diterbitkan dalam Sirok Bastra Volume 4 Nomor 2, edisi Desember 2016, yakni

\section{Prof. Dr. Agus Nuryatin, M.Hum.}

Bidang Sastra dan Pengajarannya

Universitas Negeri Semarang

Semarang, Jawa Tengah

Prof. Amrin Saragih, Ph.D., M.A.

Bidang Bahasa dan Pengajarannya

Universitas Negeri Medan

Medan, Sumatra Utara

Dr. Felicia Nuradi Utorodewo, M.Hum.

Bidang Bahasa dan Pengajarannya

Universitas Indonesia

Depok, Jawa Barat

\section{Dr. Pujiharto, M.Hum.}

Bidang Sastra dan Pengajarannya

Universitas Gadjah Mada

Yogyakarta, Daerah Istimewa Yogyakarta 


\section{DAFTAR ISI}

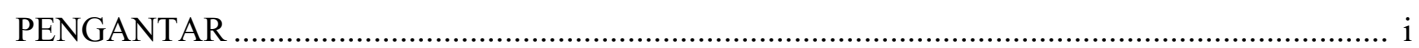

UCAPAN TERIMA KASIH UNTUK MITRA BESTARI .......................................................

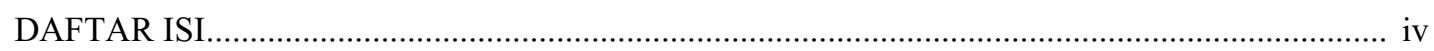

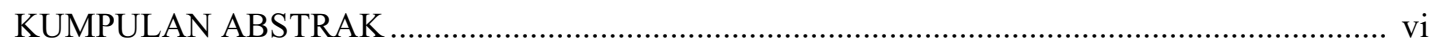

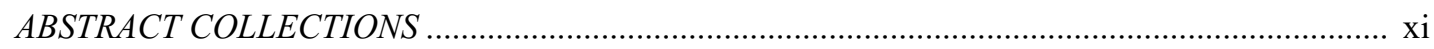

KLASIFIKASI WARNA MASYARAKAT BETAWI DI MARUNDA, JAKARTA UTARA

(Classification of Color Names in Betawi Society in Marunda, North Jakarta)

Satwiko Budiono

$101-110$

PENGARUH AKSEN BAHASA JAWA TERHADAP PEMBUNYIAN HURUF LETUP /d/

DALAM BAHASA INGGRIS

(The Influence of Javanese Accent Towards The Plosive Sound of /d/ in English)

Ayesa dan Miva Aziza $111-120$

FUNGSI DAN MAKNA PERIBAHASA DAYAK BENUAQ: KAJIAN ETNOLINGUISTIK

(The Function and Meaning of Dayak Benuaq's Proverbs: Ethnolinguistic Study)

Nurul Masfufah. $121-128$

ANALISIS RANAH RASA DENGAN PENDEKATAN NATURAL SEMANTIC

METALANGUAGE

(Taste Domain Analysis with Natural Semantic Metalanguage Approach)

Dwi Agus Erinita. $129-136$

ANALISIS PELANGGARAN MAKSIM SEBAGAI STRATEGI PENGUNGKAPAN HUMOR DALAM VIDEO HUMOR DI AKUN INSTAGRAM RIA YUNITA

(Maxim Violation Analysis as A Strategy of Humor Disclosure in Humor Video of Ria Yunita Instagram Account)

Siti Hannah Sekarwati. $137-144$

TINDAK TUTUR PERINTAH BUJUKAN KEPADA ANAK-ANAK DALAM BAHASA

BANJAR

(The Speech Act of Persuading Order to Children in Banjar Language)

Rissari Yayuk $145-152$ 
REPRESENTASI KEARIFAN LOKAL MASYARAKAT BELITUNG DALAM CERITA KERAMAT PINANG GADING

(The Representation of Belitung's Local Wisdom in Keramat Pinang Gading's Story)

Muhammad Luthendra $153-160$

STRUKTUR, BENTUK, DAN FUNGSI MANTRA ABAL

(Structure, Form, and Function of Abal Mantra)

Dede Hidayatullah $161-174$

STRUKTUR FISIK SAJAK “PEREMPUAN-PEREMPUAN PERKASA” KARYA HARTOYO ANDANGJAYA

(Physical Structure of Hartoyo Andangjaya's Poetry "Perempuan-Perempuan Perkasa")

Dwi Oktarina $175-186$

ANALISIS ARKETIPE DALAM CERITA RAKYAT LEGENDA SITI PAYUNG

(Archetype Analysis in The Folklore of Siti Payung Legend)

Irawan Syahdi 187-192 


\title{
STRUKTUR, BENTUK, DAN FUNGSI MANTRA ABAL
}

\author{
Structure, Form, and Function of Abal Mantra
}

\section{Dede Hidayatullah}

Balai Bahasa Kalimantan Selatan

Jalan A. Yani Km 32,2 Loktabat, Banjarbaru, Kalimantan Selatan

Pos-el dayatdh@gmail.com

(diterima 29 Juli 2016, disetujui 16 September 2016, revisi terakhir 28 Oktober 2016)

\begin{abstract}
Abstrak
Salah satu bahasa daerah yang sekarang sudah mengalami ambang kepunahan adalah bahasa yang dituturkan oleh masyarakat dayak Abal. Kondisi bahasa dayak Abal yang diambang kepunahan ini juga terjadi pada sastranya, terutama sastra lisannya. Penelitian ini bertujuan untuk mendeskripsikan mantra yang ada pada suku Abal, dan menguraikan struktur, bentuk, dan fungsinya dengan menggunakan metode kualitatitif. Dari hasil penelitian, Mantra Abal yang ditemukan sebanyak sebelas mantra. Tujuh mantra menggunakan bahasa tunggal, tiga mantra menggunakan bahasa campuran, dan satu mantra menggunakan bahasa asing. Kesebelas mantra ini terdiri atas mantra yang berhubungan dengan kecantikan, cinta kasih, pengobatan, dan perisai diri. Kesebelas mantra yang ditemukan sangat dipengaruhi oleh agama Islam.
\end{abstract}

Kata kunci: Dayak Abal, kepunahan, sastra lisan, mantra

\begin{abstract}
One of the local languages now that are at risk of extinction is the language spoken by the Dayak Abal people. The potentially extinction of Dayak languages conditions are also seen in literature, particularly oral literature. This study aims to describe mantras on Abal tribe, and outlines the structure, form and function using qualitative method. This research found eleven Abal mantras. Seven mantras are using a single language, three of them are using a mixed language, and one of them is using foreign language. The eleventh mantras consist of mantras related to beauty, love, medical treatment, and magical self defense. The eleventh mantras found to be highly influenced by Islam.
\end{abstract}

Keywords: Dayak Abal, extinction, oral literature, mantra

\section{PENDAHULUAN}

\subsection{Latar Belakang}

Ada banyak suku yang mendiami Provinsi Kalimantan Selatan. Setiap suku biasanya menggunakan bahasanya masing-masing dalam berkomunikasi seperti bahasa Banjar, bahasa Bakumpai, bahasa Dayak, bahasa Madura, bahasa Jawa, bahasa Bugis, bahasa Manyaan, bahasa Lawangan, bahasa Dusun Deyah, bahasa Samihin, bahasa Bajau Semayap dan bahasa Abal. Banyaknya bahasa ini akan membawa kepada penguatan kepada bahasa tertentu dan pelemahan pada bahasa yang lain. Bahasa-bahasa yang mengalami kemunduran ini akan melakukan pemertahanan. Namun, ada juga bahasa yang mengalami ambang kepunahan akibat ditinggalkan penuturnya. Apabila bahasa punah, sastra dan juga kebudayaannya akan ikut lenyap.

Salah satu bahasa daerah yang sekarang sudah mengalami ambang kepunahan adalah bahasa yang dituturkan oleh masyarakat Dayak Abal yang sering disebut dengan bahasa Abal. Suku Dayak Abal, berdiam di Muara Uya, Kabupaten Tabalong, Provinsi Kalimantan Selatan, tepatnya di Desa Simpung Layung dan Halong. Berdasarkan hasil penelitian, Suku Dayak Abal sudah tidak aktif menggunakan atau berbicara dengan bahasa Abal, baik generasi mudanya maupun generasi tuanya. (Jahdiah, dkk.: 2014:1). Bahasa Abal sendiri termasuk ke dalam rumpun bahasa Austronesia, 
yakni bahasa yang menjadi bahasa induk di wilayah Asia Tenggara.

Suku Dayak Abal hidup dari pertanian, berburu dan mengumpulkan hasil hutan. Saat ini beberapa dari masyarakat suku Dayak Abal, ada yang telah bekerja di sektor pemerintah, pabrik, toko serta telah memiliki usaha sendiri.

Suku Dayak Abal hidup sebagai minoritas di antara suku Banjar yang menjadi mayoritas di wilayah tersebut, dan saat ini secara mayoritas mereka telah memeluk agama Islam.

Suku Dayak Abal berada dalam kondisi sulit dalam mempertahankan budaya dan adat istiadatnya sendiri, karena budaya lama dari suku Abal saat ini berada diambang kepunahan, terjepit di antara budaya dan adat-istiadat mayoritas suku Banjar. Sedangkan bahasa Dayak Abal hanya tinggal diucapkan oleh para orang-orang tua, generasi muda masyarakaat Dayak Abal lebih suka berbicara dalam bahasa Banjar. Dalam kehidupan sehari-hari kenyataan yang terjadi adalah beberapa orang suku Dayak Abal lebih suka mengaku sebagai suku Banjar. Karena situasi ini beberapa peneliti sering menyatakan bahwa suku Dayak Abal dinyatakan telah punah dan sudah berasimilasi dengan suku Banjar. (Jahdiah: 2014:1)

Kondisi bahasa Abal yang diambang kepunahan ini juga terjadi pada sastranya, terutama sastra lisannya. Hal ini terlihat pada mulai berkurangnya istilah, dan ungkapan, serta pribahasa yang digunakan dalam kehidupan mereka. Bahkan, untuk cerita rakyatnya sudah bisa dikatakan punah. Kepunahan cerita rakyatnya ini disebabkan karena generasi muda suku dayak Abal tidak lagi mengenal bahasa Abal. Mereka menggunakan bahasa Banjar dalam komunikasi sehari-hari. Sedangkan cerita rakyat sendiri biasa dituturkan dari secara lisan dari orang tua kepada anaknya dengan bahasanya sendiri.

Penyelamatan bahasa Abal berarti juga menyelamatkan sastra Abal. Namun sangat disayangkan inventarisasi terhadap sastra Abal belum pernah dilakukan. Pada tahun 2014, ada tim penelitian yang melakukan perekaman bahasa kosakata bahasa Abal. Pada kegiatan itu, tim ini juga berupaya merekam sastra Abal, tetapi sangat di sayangkan tim peneliti hanya sedikit dapat merekam sastra lisan Abal.

Sastra lisan Abal yang dapat direkam diantaranya adalah mantra. Mantra atau bacaan merupakan ragam puisi lisan yang berbentuk puisi bebas dan berpotensi memiliki kekuatan gaib. Banyak kajian tentang puisi lisan yang tidak menyentuh mantra sebagai objek karena ada kesan yang mengandaikan bahwa mantra bukan puisi lisan (Saputra, 2007: 93). Mantra ini dipercaya oleh masyarakatnya mempunyai fungsi yang sangat banyak dan hanya dimiliki oleh orang-orang tertentu saja yang bergelut dengan hal yang bersifat kebatinan, seperti ulama, tuan guru, tabib, dukun, dan pawang. Akan tetapi tidak menutup kemungkinan orang biasa juga mempunyai dan menguasai mantra-mantra tertentu, dengan syarat-syarat tertentu pula. (Tim Penyusun, 2005: 15) Peneliti menemukan ada 11 mantra yang masih digunakan oleh suku Abal. Kesebelas Mantra itu didapat dari satu narasumber. Mantra, menurut kepercayaan masyarakat Abal, tidak bisa sembaranga diberkan kepada penutur abal. Mantra yang memiliki unsur magis ini tidak sembarang orang dapat mencatatnya dan memilikinya kecuali dengan berbagai sesajian.

Ada beberapa penelitian yang memfokuskan perhatian pada mantra antara lain, seperti Patton E. Burchett (2008) tentang fenomena kemagisan mantra, Daod (2010) tentang mantra dan dukun di Malaysia, Saputra (2007) tentang struktur mantra Using, konvensi, konsep kelisanan dan fungsinya, Maknuna (2013) tentang struktur, formula, dan fungsi mantra di Situbundo, Kasmilawati (2012) tentang struktur mantra Dayak Deyah, Suwatno (2012) tentang bentuk dan isi mantra. Sunarti, dkk. (1978) dan Tim Peneliti dari Balai Bahasa Provinsi Kalimantan Selatan (2005), Rohim (2012) yang mendiskripsikan tentang bentuk mantra Banjar berdasarkan fungsinya dan nilai budaya. Dede Hidayatullah (2009) mendiskripsikan jenis mantra Banjar berdasarkan penggunaannya. Penelitian tentang mantra Abal belum pernah dilakukan, baik itu tentang struktur, bentuk, dan fungsi mantra Abal.

\subsection{Masalah}

Berdasarkan uraian di atas, penelitian ini mengangkat bagaimanakah struktur, bentuk dan fungsi mantra Abal.

\subsection{Tujuan}


Penelitian ini bertujuan untuk mendeskripsikan mantra yang ada pada suku Abal, dan menguraikan struktur, bentuk dan fungsinya. Penelitian ini sangat penting dilakukan sebagai upaya penyelamatan dan pelestarian terhadap sastra lisan suku Abal, dalam hal ini mantra agar tetap terjaga dan lestari.

\subsection{Metode Penelitian}

Penelitian ini merupakan penelitian kualitatif. Penelitian ini akan mendata mantra Abal, kemudian menjelaskan tentang struktur mantra Abal secara rinci. Setelah itu, akan diuraikan mantra Abal berdasarkan klasifikasi bentuk dan fungsinya pada masyarakat Abal. Karena metode ini digunakan untuk mendeskripsikan satu varibel dengan menguraikannya serinci mungkin. (Furchan, 1982: 440),

Data primer penelitian ini adalah mantra-mantra Abal yang didapat dari hasil wawancara dengan para tokoh adat dan tokoh agama suku Abal di Kalimantan Selatan. Sedangkan data sekunder dari penelitian ini adalah buku-buku yang berkaitan tentang mantra.

Dari semua data tersebut, peneliti menganalisis strukturnya. Setelah itu, peneliti kemudian mengklasifikasi, mendeskripsikan dan menganalisa berdasarkan bentuknya, fungsinya, dan bahasa yang digunakannya dengan menggunakan pendekatan kualitatif.

\section{KERANGKA TEORI}

Sastra lisan adalah karya yang penyebarannya disampaikan dari mulut ke mulut secara turun temurun. Sastra lisan biasanya mempunyai beberapa ciri, yakni: (1) penyebarannya, baik dari segi waktu maupun ruang melalui mulut; (2) lahir di masyarakat yang bercorak tradisional; menggambarkan ciri-ciri budaya suatu masyarakat; (4) bercorak puitis, teratur, dan berulang-ulang; (6) tidak mementingkan fakta dan kebenaran, tetapi mempunyai fungsi yang penting dalam masyarakat yang bersangkutan; (7) memiliki berbagai versi; dan (8) menggunakan gaya bahasa lisan (sehari-hari), mengandung dialek, kadang-kadang diucapkan tidak lengkap; dan (9) cerita lisan itu merupakan proyeksi emosi manusia yang paling jujur manifestasinya. (Danandjaya 2002:3-5) Yang penting dalam sastra lisan ialah isi karya sastra, tujuannya, serta hal-hal yang tersirat dalam sastra itu yang berkaitan dengan masyarakat. Selain itu, yang dipentingkan ialah dampak sosial karya sastra itu (Wellek, 1989:111).

Salah satu jenis hasil sastra lisan Indonesia ialah mantra. Mantra adalah gubahan bahasa yang diresapi oleh kepercayaan kepada dunia gaib dan sakti. Mantra itu mempunyai seni kata yang khas pula. Kata-katanya dipilih secermat-cermatnya, kalimatnya tersusun dengan rapi, begitu pula dengan iramanya. Isi dipertimbangkan sedalam-dalamnya. Ketelitian dan kecermatan memilih kata-kata, menyusun larik, dan menetapkan irama itu sangat diperlukan, terutama yang menimbulkan tenaga gaib. Hal ini dapat kita pahami karena suatu mantra yang diucapkan tidak dengan semestinya, kurang katanya, salah lagunya, dan sebagainya akan hilang pula kekuatannya, tidak akan menimbulkan tenaga gaib lagi. Sedang tujuan utama dari suatu mantra ialah untuk menimbulkan tenaga gaib (Djamaris, 1996:20). Sedangankan Menurut Anwar, (2005: 213) mantra adalah perkataan atau kalimat yang dapat mendatangkan daya gaib, jampi, dan pesona. Adapun menurut Zulfanur dkk. (1999: 12) mantra adalah gubahan bahasa yang diresapi oleh kepercayaan kepada dunia gaib dan sakti”. Menurut Kosasih (2012:14) mantra adalah bentuk puisi atau gubahan bahasa yang diresapi oleh kepercayaan akan dunia gaib. Irama bahasa sangatlah dipentingkan dengan maksud untuk menciptakan nuansa magis, mantra timbul dari hasil imajinasi atas dasar kepercayaan animisme.

Alisjahbana (dalam Djamaris, 1996:20) menggolongkan mantra ini ke dalam golongan bahasa berirama, sedangkan bahasa berirama ini termasuk ke dalam puisi lama. Dalam bahasa berirama itu, irama bahasa sangat dipentingkan, terutama dalam mantra diutamakan sekali irama yang kuat dan teratur untuk membangkitkan tenaga gaib. Pemilihan kata dalam mantra dilakukan dengan cara yang lebih selektif, intensif, dan serius. Hal ini dimaksud agar membangkitkan kekuatan gaib. Pada mulanya. Mantra dan puisi mempunyai kesamaan seperti (a) berupa ungkapan yang terikat, (b) dipaparkan secara lisan, (c) diucapkan oleh orang-orang tertentu. Meskipun dalam perkembangannya puisi telah mengalami perubahan tujuan, yakni sebagai pengungkap dan pengekpresi diri 
ataupun sebagai penghibur namun pengaruh mantra dalam puisi-pusi Sutarji Cazoum Bahri.

Mantra, menurut Koentjaraningrat (1981:77) adalah bagian dari teknik ilmu gaib yang berupa kata-kata dan suara-suara yang sering tidak berarti, tetapi dianggap berisi kesaktian atau kekuatan mengutuk. Mantra terdapat di dalam kesustraan daerah di seluruh Indonesia. Mantra berhubungan dengan sikap religius manusia. Untuk memohon sesuatu kepada Tuhan diperlukan kata-kata pilihan yang berkekuatan gaib, yang oleh penciptanya dipandang mempermudah kontak dengan Tuhan. Dengan demikian, apa yang diminta (dimohon) oleh pengucap mantra itu dapat dipenuhi oleh Tuhan.

Mantra Abal yang ditemukan sangat dipengaruhi oleh agama Islam. Hal ini terjadi karena mayoritas masyarakat Abal. Hal ini menyebabkan mantra yang digunakan dan diayakini mengandung unsur kemagisan ini sangat dipengaruhi agama Islam. Selain itu, mantra-mantra Abal ini juga dipengaruhi unsur-unsur budaya yang merupakan warisan dari leluhur.

Penelitian tentang mantra ini akan menggunakan teori struktur mantra. Oleh karena itu, akan diuraikan teori struktur secara umum dan juga teori struktur mantra. Menurut Siswantoro, (2011:13) "Struktur adalah bentuk keseluruhan yang kompeleks". Setiap objek, atau peristiwa adalah pasti sebuah struktur, yang terdiri dari berbagai unsur yang setiap unsurnya tersebut menjalin hubungan. Selanjutnya menurut Hehahia dan Farlin, (2008:417) "Struktur adalah cara bagaimana sesuatu disusun, susunan, bangunan, kerangka. Aminudin (2004:136) "Bangun Struktur puisi adalah unsur pembentuk puisi yang dapat diamati secara visual". Unsur tersebut akan meliputi bunyi, kata, larik atau baris, bait dan tipografi.

Struktur Mantra secara umum, menurut Maknuna (2013, lih. Kasmilawati, 2012) terbentuk dari unsur-unsur yang meliputi unsur judul, unsur pembuka, unsur sugesti, dan unsur tujuan/penutup.

Judul merupakan unsur pokok yang penting. Dengan adanya judul pada mantra, dengan mudah dapat diketahui isi dari mantra tersebut. Dalam sebuah mantra, unsur judul merupakan salah satu unsur pokok karena dengan adanya judul dalam sebuah mantra dapat mempermudah membedakannya, dan terlihat jelas tujuan dan fungsi mantra yang bersangkutan.

Unsur pembuka adalah kata pertama yang terdapat pada mantra yang berisi salam pembuka. Biasanya menggunakan kata-kata yang diadopsi dari bahasa Arab, bahasa Sanskerta (Hindu), dan bahasa Jawa. Komponen pembuka merupakan pengakuan tunduk dan mohon perlindungan Allah penguasa semesta.

Unsur sugesti adalah unsur yang berisi metafora atau simbol yang dianggap memiliki kekuatan gaib pada mantra yang diucapkan atau dalam rangka membantu membangkitkan potensi kekuatan magis atau gaib pada mantra. Unsur yang membangun pada mantra-mantra yang dikumpulkan adalah unsur segesti.

Unsur Tujuan adalah sesuatu yang hendak dicapai oleh seorang dukun atau pemantra dalam menggunakan mantra atau mengamalkan mantra. Unsur tujuan pada mantra merupakan suatu permohonan atau keinginan agar dengan mantra-mantra yang ia ucapkan dapat berfungsi sebagai menyembuhkan penyakit, memanggil hujan, untuk diri sendiri, dan lain-lainnya. Unsur tujuan juga berfungsi untuk membedakan mantra satu dengan mantra yang lain karena tiap-tiap mantra memiliki tujuannya masing-masing.

Adapun bentuk mantra, menurut Suwatno (2012:4) bisa berbentuk wacana, bisa juga hanya terdiri atas satu, dua, atau tiga kalimat, bahkan bisa juga terdiri dari kata yang tidak mempunyai makna, tetapi mempunyai daya magis. Mantra juga bisa berbentuk sajak, pantun dan juga liris.

Adapun penggunaan bahasa dalam mantra, sebuah mantra bisa saja terdiri dari satu bahasa saja, baik itu bahasa asli ataupun bahasa yang mempengaruhi masyarakat pengguna mantra baik dari segi agama maupun budaya. Selain itu, bisa juga bahasa yang digunakan terdiri dari dua bahasa yang salaing melengkapi dalam satu mantra (Hidayatullah, 2014:3).

\section{PEMBAHASAN}

\subsection{Mantra Abal}

Mantra Abal yang ditemukan ada sebelas mantra. Tujuh mantra menggunakan bahasa tunggal, tiga mantra menggunakan bahasa campuran, dan satu mantra 
menggunakan asing yaitu bahasa Arab. Tiga mantra yang menggunakan bahasa campuran menggunakan kalimat zikir dalam bahasa Arab untuk menutup محمّد لوالإله إلا اله (laailaha illallah Muhammadar Rasulullah). Penggunaan kalimat zikir ini menunjukkan kuatnya pengaruh Islam dalam mantra Abal. Bahasa yang digunakan dalam mantra Abal ini sangat dipengaruhi oleh kosakata bahasa Banjar. Pada awalnya, peneliti mengira mantra yang ditemukan itu adalah mantra Banjar yang dipakai oleh orang Abal. Namun, setelah diteliti lebih lanjut, ternyata ada perbedaan antara mantra Banjar dengan mantra Abal, baik itu dari mantranya, maupun dari simbol yang digunakan.

Adapun kesebelas mantra itu adalah sebagai berikut.

Mantra Abal ${ }^{1}$

\subsubsection{Untuk Menundukkan Orang Yang Disukai (1)}

Sum lata tumbar wana

Anak pandu ginda wata

Kurung Raden Jaya Pirana

Aku memandang urang

Yang kupuja hari ini.

Mantra ini digunakan ketika akan bertemu dengan orang yang disukai. Cara penggunaan mantra ini adalah dengan meniupkan mantra ini ke minyak yang dibuat dari kelapa merah yang tidak terlalu tua. Kemudian minyak yang sudah ditiup tadi diambil sedikit dengan jari dan dituliskan di dahi dengan cara menyilang.

\subsubsection{Untuk Menundukkan Orang Yang Disukai (2)}

Malati kambang malati

Ditawak ka pintang hati

Si lundang kamarasan

Tumpah darah nining kawadun

Runduk kasih badannya si ....(sebut nama orang yang disukai)

Maniring cahaya mukaku.

Cara penggunaannya sama dengan mantra yang pertama, yaitu dengan meniupkan mantra ini ke minyak yang dibuat dari kelapa merah yang tidak terlalu tua. Kemudian minyak yang sudah ditiup tadi diambil sedikit dengan jari dan dituliskan di dahi dengan cara menyilang, setelah itu bertemu dengan orang yang dicintai atau diinginkan.

\subsubsection{Mantra Bapupur (khusus untuk perempuan)}

Kariring kata Samar

Aku datang ditangisi

Aku mantuk dimarasi

Takaulas takaningasih

Takaulas takaning gila

Gila kasih sayanglah si ....(sebut nama orang yang disukai) kepadaku

Caranya mantra ini ditiup ke bedak yang masih berupa biji seperti kelereng, kemudian bedak tadi dicampur dengan air dan diusapkan ke wajah. Mantra ini khusus digunakanan oleh perempuan saja.

\subsubsection{Menundukkan Orang Yang Dicintai}

Air balumbang dalam batu

Bulan purnama empat belas cahayaku

Bintang bahambur kiri kananku

Tadung malungak di ubun-ubunku

Matahari memancar dari dadaku

Takaulas takaningasih

Takaulas takaninggaras

Tunduk kasih maras sayang badan si ....(sebut nama orang yang dicintai)

Memandang mukaku

Caranya mantra ini ditiup ke air, kemudian disapukan ke wajah, ketika ingin bertemu dengan orang yang diinginkan atau yang dicintai.

\subsubsection{Mantra Untuk Mengetahui Orang Itu Mau Atau Tidak Lawan Kita}

Sir manisan rap gunung naga putih

Jikalau si ...(nama) handak wan aku

Manjapai dada antara muka

Jikalau si ... (nama) kada handak wan aku

Manjapai tasdik antara belakang

Cara: Baca 3 kali, tiup ke orang yang dimaksud, bila dia memegang muka, berarti dia mau dan cinta dengan 
kita, tetapi bila dia memegang belakang, berarti dia tidak mau dan cinta dengan kita.

\subsubsection{Mantra Menundukkan Kekasih Lewat Pandangan Mata}

Hayali hayalullah hayal mani bayanullah Uurangan matanya tagantung uurangan mataku Uurangan mataku tagantung uurangan matanya Takaulas takadingasih

\section{Takaulas takadingaras}

Tunduk kasih maras sayang badan si... (nama orang yang mau ditundukkan)

lawan aku.

Cara: Baca 3 kali, tiup ke mata sendiri, kemudian dibawa untuk saling berpandangan dengan orang yang dituju.

\subsubsection{Mantra Menundukkan Kekasih Lewat Suara}

Sirihku si runtai tali gambirku parasuk badan pinangku si pinang buntar

kapurku si guna palit

tawak ka batu batu rakai

tawak ka gunung gunung runtuh

turun ka banyu banyu tamandak

angin lalu angin tahanti

mangakak halilintar

urang tadangar suaraku Daud

urang tapandang kurihingku yusuf.

Cara: Baca ka kinangan 3 kali, bawa manginang. Luwak sapahnya lalu taguk banyunya. Lalu banyanyi atau bapandir kaurang yang dituju.

\subsubsection{Mantra Mampihi Urang Karindangan}

Durna mandak

Sirna mandak

\section{Tatutup takuncilah}

Hati ....(nama orang yang karindangan) lawan si ...(nama orang yang dimaulah karindangan)

$$
\begin{aligned}
& \text { Berkat لإله إلا الله } \\
& \text { محمّد رسول الله }
\end{aligned}
$$

Cara: Tiup ke air minum, kemudian minumkan ke orang yang sedang jatuh cinta, airnya jangan dihabiskan. Sisa airnya di buang ke comberan.

\subsubsection{Mantra Sangga-Sangga Dari Orang Jahat}

Ruh kayu rumbang raya,

Duduk putar raja putar

Putar Allah

Putar Muhammad

Putar baginda Ali

Summa balik kia

Siapa ada perbuatan jahat atas diriku

Tabulik

Taputar pada dirinya jua berkat

محمّد رسول اله ل لإله إلا اله

Caranya mantra ini dibaca 3x tiap-tiap mau tidur.

\subsubsection{Mantra Sangga-Sangga}

Allahumma kata sangga

Sangga Allah

Sangga Muhammad

Sangga baginda Ali

Allah yang ampun sangga

Nabi Muhammad yang manyangga

محمّد رسول الله لإله إل الله

\subsubsection{Mantra Untuk Mengobati Sakit Pinggang}

Allahumma shalli 'alaa sayyidina Muhammad

Mantra ini dibaca tatkala bangun dari tidur sambil melingkarkan tangan ke pinggang dengan ibu jari saling bersentuhan. Kemudian kedua tapak tangan tadi diputar kebelakang sambil diurut ke bawah.

Dari sebelas mantra Abal ini dapat diklasifikasikan menjadi empat jenis mantra, yaitu:

1. Mantra yang berhubungan dengan kecantikan. Mantra jenis ini termasuk dalam mantra mantra simpatik. Pengguna mantra ini biasanya bertujuan untuk dipandang orang manis, dihargai dan dimuliakan, dimudahkan atau dilancarkan, dimenangkan, dilebihkan dari yang lain atau dikasihi orang, tidak untuk memaksa atau merugikan orang lain. Dalam bahasa Banjar, Mantra jenis ini disebut mantra pitua (tim penyusun, 2005:8). Mantra Abal yang termasuk jenis ini adalah mantra Mantra Bapupur. 
2. Mantra yang berhubungan dengan cinta kasih. Mantra jenis ini biasanya berusaha menundukkan orang lain agar mencintai si penggunanya atau tunduk pada penggunanya. Mantra jenis ini termasuk dalam mantra agresif. Mantra ini disebut juga dalam bahasa Banjar mantra pirunduk. Mantra Abal yang termasuk dalam jenis ini adalah mantra untuk menundukkan orang yang disukai 1, untuk menundukkan orang yang disukai, mantra menundukkan orang yang dikahandaki, mantra untuk mengetahui orang itu mau atau tidak lawan kita, mantra menundukkan kekasih lewat pandangan mata, dan mantra menundukkan kekasih lewat suara.

3. Mantra yang berhubungan dengan pengobatan. Mantra Abal yang termasuk dalam jenis ini adalah mantra maampihi urang karindangan dan mantra untuk mengobati sakit pinggang. Mantra ini digunakan untuk menghilangkan rasa cinta pada orang yang sedang dimabuk cinta, baik itu karena memang cinta ataupun karena terkena mantra cinta dari orang lain. mantra pengobatan ini terbagi atas dua jenis, yaitu mantra yang mengobati penyakit biasa dan mantra yang mengobati penyakit karena terkena mantra atau ilmu gaib dari orang lain. mantra untuk mengobati sakit pinggang berguna untuk mengobati penyakit biasa. Sedang mantra maampihi urang karindangan digunakan untuk mengobati dari penyakit terkena ilmu gaib dari orang lain.

4. Mantra yang berhubungan dengan perisai diri atau perlindungan diri. Mantra yang termasuk dalam jenis ini adalah mantra Sangga-sangga dan mantra sangga-sangga dari orang jahat. Kedua mantra ini bertujuan agar si penggunanya tidak terkena ilmu gaib dan/atau mahluk gaib.

Dari sebelas mantra Abal ini ternyata yang paling banyak adalah yang berhubungan dengan cinta kasih yaitu sebanyak 6 mantra, sedangkan lima mantra yang lain terbagi ke tiga jenis lainnya, yaitu, pengobatan dua mantra, perisai diri dua mantra, dan satu mantra yang berhubungan dengan kecantikan.

\subsection{Struktur Mantra Abal}

Secara umum, menurut Maknuna (2013, lih. Kasmilawati, 2012) mantra terbentuk dari unsur-unsur yang meliputi unsur judul, unsur pembuka, unsur sugesti, dan unsur tujuan/penutup. Semua mantra Abal yang didapatkan peneliti, yaitu 11 mantra, memiliki judul mantra. Namun, tidak semua memiliki unsur pembuka dan unsur tujuan. Ada yang hanya berisi judul dan unsur sugesti sementara unsur tujuan tersimbol dalam unsur sugesti. untuk lebih jelasnya akan diuraikan struktur mantra Abal ini sebagai berikut.

Tabel 1. Struktur mantra Untuk Menundukkan Orang Yang Disukai 1

\begin{tabular}{|l|l|}
\hline Unsur Struktur & Isi Unsur Struktur \\
\hline Unsur Judul & Untuk Menundukkan Orang Yang Disukai 1 \\
\hline Unsur Pembuka & Sum lata tumbar wana \\
\hline Unsur Sugesti & $\begin{array}{l}\text { Anak pandu ginda wata } \\
\text { Kurung Raden Jaya Pirana }\end{array}$ \\
\hline Unsur Tujuan & $\begin{array}{l}\text { Aku memandang urang } \\
\text { Yang kupuja hari ini. }\end{array}$ \\
\hline
\end{tabular}

Tabel 2. Struktur mantra Untuk Menundukkan Orang Yang Disukai 2

\begin{tabular}{|l|l|}
\hline Unsur Struktur & Isi Unsur Struktur \\
\hline Unsur Judul & Menundukkan Orang Yang Disukai 2 \\
\hline Unsur Pembuka & Malati kambang malati \\
\hline \multirow{3}{*}{ Unsur Sugesti } & $\begin{array}{l}\text { Ditawak ka pintang hati } \\
\text { Si lundang kamarasan } \\
\text { Tumpah darah nining ka wadun }\end{array}$ \\
\hline
\end{tabular}




\begin{tabular}{|l|l|}
\hline $\begin{array}{l}\text { Unsur Tujuan/ } \\
\text { unsur penutup }\end{array}$ & $\begin{array}{l}\text { Runduk kasih badannya si ....(sebut nama orang yang disukai) } \\
\text { Maniring cahaya mukaku. }\end{array}$ \\
\hline
\end{tabular}

Tabel 3. Struktur Mantra Bapupur (khusus untuk perempuan)

\begin{tabular}{|l|l|}
\hline Unsur Struktur & Isi Unsur Struktur \\
\hline Unsur Judul & Mantra Bapupur (khusus untuk perempuan) \\
\hline Unsur Pembuka & Kariring kata Samar \\
\hline Unsur Sugesti & $\begin{array}{l}\text { Aku mantuk dimarasi } \\
\text { Takaulas takaningasih } \\
\text { Takaulas takaning gila }\end{array}$ \\
\hline $\begin{array}{l}\text { Unsur Tujuan/ } \\
\text { unsur penutup }\end{array}$ & Gila kasih sayanglah si ....(sebut nama orang yang disukai) kepadaku \\
\hline
\end{tabular}

Tabel 4. Struktur mantra Menundukkan Orang Yang Dihandaki (dicintai)

\begin{tabular}{|l|l|}
\hline Unsur Struktur & Isi Unsur Struktur \\
\hline Unsur Judul & Menundukkan Orang Yang Dihandaki (dicintai) \\
\hline Unsur Pembuka & Air balumbang dalam batu \\
\hline \multirow{5}{*}{ Unsur Sugesti } & $\begin{array}{l}\text { Bintang bahamama empat belas cahayaku } \\
\text { Tadung malungak di ubun-ubunku } \\
\text { Matahari memancar dari dadaku } \\
\text { Takaulas takaningasih } \\
\text { Takaulas takaninggaras }\end{array}$ \\
\hline Unsur Tujuan/ & $\begin{array}{l}\text { Tunduk kasih maras sayang badan si ....(sebut nama orang yang dicintai) } \\
\text { unsur penutup }\end{array}$ \\
\hline
\end{tabular}

Tabel 5. Struktur mantra Sagan Mangatahui Orang Itu Mau Atawa Kada Lawan Kita

\begin{tabular}{|l|l|}
\hline Unsur Struktur & Isi Unsur Struktur \\
\hline Unsur Judul & Mantra Sagan Mangatahui Orang Itu Mau Atawa Kada Lawan Kita \\
\hline Unsur Pembuka & Sir manisan rap gunung naga putih \\
\hline Unsur Sugesti & -- \\
\hline $\begin{array}{l}\text { Unsur Tujuan/ } \\
\text { unsur penutup }\end{array}$ & $\begin{array}{l}\text { Jikalau si ...(nama) handak wan aku } \\
\text { Manjapai dada antara muka } \\
\text { Jikalau si ... (nama) kada handak wan aku } \\
\text { Manjapai tasdik antara belakang }\end{array}$ \\
\hline
\end{tabular}

Tabel 6. Struktur mantra Menundukkan Kekasih Lewat Pandangan Mata

\begin{tabular}{|l|l|}
\hline Unsur Struktur & Isi Unsur Struktur \\
\hline Unsur Judul & Mantra Menundukkan Kakasih Lewat Pandangan Mata \\
\hline Unsur Pembuka & Hayali hayalullah hayal mani bayanullah \\
\hline \multirow{3}{*}{ Unsur Sugesti } & $\begin{array}{l}\text { Uurangan matanya tagantung uurangan mataku } \\
\text { Uurangan mataku tagantung uurangan matanya } \\
\text { Takaulas takadingasih } \\
\text { Takaulas takadingaras }\end{array}$ \\
\hline
\end{tabular}




\begin{tabular}{|l|l|}
\hline $\begin{array}{l}\text { Unsur Tujuan/ } \\
\text { unsur penutup }\end{array}$ & Tunduk kasih maras sayang badan si ....(sebut nama orang yang dicintai) lawan aku \\
\hline
\end{tabular}

Tabel 7. Struktur mantra Menundukkan Kekasih Lewat Suara

\begin{tabular}{|l|l|}
\hline Unsur Struktur & Isi Unsur Struktur \\
\hline Unsur Judul & Mantra Menundukkan Kekasih Lewat Suara \\
\hline Unsur Pembuka & $\begin{array}{l}\text { Sirihku si runtai tali } \\
\text { gambirku parasuk badan } \\
\text { pinangku si pinang buntar } \\
\text { kapurku si guna palit }\end{array}$ \\
\hline Unsur Sugesti & $\begin{array}{l}\text { tawak ka batu batu rakai } \\
\text { tawak ka gunung gunung runtuh } \\
\text { turu banyu banyu tamandak } \\
\text { angin lalu angin tahanti } \\
\text { mangakak halilintar } \\
\text { urang tadangar suaraku Daud } \\
\text { urang tapandang kurihingku yusuf. }\end{array}$ \\
\hline $\begin{array}{l}\text { Unsur Tujuan/ } \\
\text { unsur penutup }\end{array}$ & -- \\
\hline
\end{tabular}

Tabel 8. Struktur mantra Maampihi Urang Karindangan

\begin{tabular}{|c|c|}
\hline Unsur Struktur & Isi Unsur Struktur \\
\hline Unsur Judul & Mantra Maampihi Urang Karindangan \\
\hline Unsur Pembuka & $\begin{array}{l}\text { Durna mandak } \\
\text { Sirna mandak }\end{array}$ \\
\hline Unsur Sugesti & -- \\
\hline $\begin{array}{l}\text { Unsur Tujuan/ } \\
\text { unsur penutup }\end{array}$ & $\begin{array}{l}\text { Tatutup takuncilah } \\
\text { Hati ....(nama orang yang karindangan) lawan si ...(nama orang yang dimaulah } \\
\text { karindangan) } \\
\text { Berkat لإله إل الشّد رسول اله }\end{array}$ \\
\hline
\end{tabular}

Tabel 9. Struktur mantra Sangga-sangga Dari Orang Jahat

\begin{tabular}{|c|c|}
\hline Unsur Struktur & Isi Unsur Struktur \\
\hline Unsur Judul & Mantra Sangga-sangga dari Orang Jahat \\
\hline Unsur Pembuka & Ruh kayu rumbang raya, \\
\hline Unsur Sugesti & $\begin{array}{l}\text { Duduk putar raja putar } \\
\text { Putar Allah } \\
\text { Putar Muhammad } \\
\text { Putar baginda Ali } \\
\text { Summa balik kia }\end{array}$ \\
\hline $\begin{array}{l}\text { Unsur Tujuan/ } \\
\text { unsur penutup }\end{array}$ & $\begin{array}{l}\text { Siapa ada perbuatan jahat atas diriku } \\
\text { Tabulik } \\
\text { Taputar pada dirinya jua berkat } \\
\text { محسّد رسول الله لإله إل الله }\end{array}$ \\
\hline
\end{tabular}


Tabel 10. Struktur mantra Sangga-sangga

\begin{tabular}{|c|c|}
\hline Unsur Struktur & Isi Unsur Struktur \\
\hline Unsur Judul & Mantra Sangga-sangga \\
\hline Unsur Pembuka & Allahumma kata sangga \\
\hline Unsur Sugesti & $\begin{array}{l}\text { Sangga Allah } \\
\text { Sangga Muhammad } \\
\text { Sangga baginda Ali }\end{array}$ \\
\hline $\begin{array}{l}\text { Unsur Tujuan/ } \\
\text { unsur penutup }\end{array}$ & $\begin{array}{l}\text { Allah yang ampun sangga } \\
\text { Nabi Muhammad yang manyangga } \\
\text { محمّد رسول الله لإله إل اله }\end{array}$ \\
\hline
\end{tabular}

Tabel 11. Struktur mantra Mengobati Sakit Pinggang

\begin{tabular}{|l|l|}
\hline Unsur Struktur & Isi Unsur Struktur \\
\hline Unsur Judul & Mantra Untuk Mengobati Sakit Pinggang \\
\hline Unsur Pembuka & -- \\
\hline Unsur Sugesti & Allahumma shalli 'alaa sayyidina Muhammad \\
\hline $\begin{array}{l}\text { Unsur Tujuan/ } \\
\text { unsur penutup }\end{array}$ & -- \\
\hline
\end{tabular}

Dari kesebelas struktur yang diuraikan dalam tabel diatas dapat disimpulkan bahwa semua mantra Abal ini mempunyai unsur judul semua. Adapun unsur pembuka hanya tidak dimiliki oleh satu mantra saja, yaitu mantra untuk mengobati sakit pinggang, sedangkan mantra yang lain semuanya memiliki unsur pembuka. Sedangkan Unsur Sugesti hampir dimiliki oleh semua mantra Abal ini kecuali mantra sagan mangatahui orang itu mau atawa kada lawan kita dan mantra maampihi urang karindangan. Kedua sugesti mantra ini tersimbol secara tersirat dalam unsur tujuan. Demikian juga dengan unsur tujuan/unsur penutup hampir dimiliki semua mantra Abal kecuali mantra Menundukkan Kekasih Lewat Suara dan Mantra untuk mengobati sakit pinggang. Unsur judul dalam mantra Abal ini kebanyakannya menggunakan bahasa Indonesia dan bahasa Banjar. Unsur judul ini dibuat untuk memudahkan penggunanya dalam merapal mantra ini.

Adapun unsur pembuka dalam mantra Abal ini biasanya menggunakan kata atau kalimat yang tidak mengandung arti, tetapi mengandung daya magis, seperti sum lata tumbar wana, dan sir manisan rap rap gunung naga putih. Ada juga yang menggunakan sampiran seperti pada pantun, tetapi mantra tidak berbentuk pantun, seperti Air balumbang dalam batu, Malati kambang malati, dan Sirihku si runtai tali gambirku parasuk badan pinangku si pinang buntar kapurku si guna palit. Ada juga yang menggunakan bahasa campuran dengan bahasa Arab, tetapi juga tidak mempunyai makna hanya permainan bunyi saja. Unsur pembuka seperti ini terdapat pada Hayali hayalullah hayal mani bayanullah.

Simbol dan metafora yang digunakan dalam unsur sugesti terbagi kepada dua, yaitu simbol yang bersumber dari pengetahuan dan keyakinan agama dan simbol yang berasal dari budaya Abal. Simbol yang bersumber dari pengetahuan agama ini seperti penggunaan nama Nabi, seperti Nabi Daud untuk menyimbolkan kebagusan suara, Nabi Yusuf untuk menyimbolkan ketampanan, Nabi Muhammad dan Ali bin Abi thalib (sahabat, keponakan, dan menantu Nabi Muhammad) untuk menyakatan kekuatan keyakinan sebagai perisai diri. Simbol yang bersumber dari pengetahuan dan keyakinan agama ini menunjukkan pengaruh Islam yang sangat kuat pada masyarakat Abal dan juga kereligiusan masyarakat Abal. Sedangkan simbol budaya bisa kita lihat pada contoh tawak ka batu batu rakai, tawak ka gunung gunung runtuh, turun ka 
banyu banyu tamandak, angin lalu angin tahanti, mangakak halilintar. Kata gunung runtuh, angin tahanti, banyu tamandak, dan mangakak halilintar menandakan adanya sebuah kekuatan yang bisa mengatur alam. Simbol ini merupakan simbol budaya yang menunjukkan kedekatan masyarakat Abal dengan alam.

Kalimat yang biasanya digunakan dalam unsur tujuan atau penutup ini biasanya berkaitan dengan judul dan tujuan digunakannya mantra. Selain itu, ada mantra yang menggunakan kata penutup berkat laailaha illallah Muhammadur Rasulullah. Penggunan kata zikir ini ada pada mantra sangga atau pelindung dan mantra pengobatan. Penggunaan kata ini berkaitan dengan keyakinan penyerahan diri dari pemantra agar mantranya manjur dan juga berkaitan dengan keyakinannnya sebagai penganut Islam yang taat, serta keyakinannya bahwa hanya Allah lah yang bisa mengobati dan melindungi seseorang dari berbagai bala bencana, bahaya, dan kejahatan orang lain. ada juga mantra yang tidak menggunakan unsur penutup seperti pada mantra Menundukkan Kekasih Lewat Suara. Unsur tujuannya tersirat pada unsur sugesti, yang bisa dilihat dari maknanya.

\subsection{Bentuk mantra Abal}

Mantra, menurut Suwatno (2012: 4) bisa berbentuk wacana, bisa juga hanya terdiri atas satu, dua, atau tiga kalimat, bahkan bisa juga terdiri dari kata yang tidak mempunyai makna, tetapi mempunyai daya magis. Mantra juga bisa berbentuk syair, pantun dan juga liris. Sedangkan Dede (2016: 16) mengelompokkan mantra menjadi empat, yaitu berbentuk syair, berbentuk pantun, berbentuk liris dan berbentuk bebas. Adapun mantra Abal yang ditemukan ini hampir semuanya berbentuk puisi bebas yang terdiri dari beberapa kalimat, kecuali pada mantra untuk mengobati sakit pinggang. Dari 11 mantra yang diteliti tidak ditemukan ada mantra yang berbentuk syair, pantun, ataupun prosa liris.

\subsection{Fungsi Mantra Abal}

Secara umum Mantra mempunyai fungsi di masyarakat. Hal ini disampaikan oleh Bascom dalam Danandjaja (1984:19) mengemukakan empat fungsi mantra, yaitu Mantra dapat berfugsi sebagai sistem proyeksi, yaitu pencerminan angan-angan suatu kolektif; Mantra merupakan alat pengesahan pranatapranata dalam lembaga kebudayaan; Mantra merupakan sarana pendidikan; Mantra merupakan alat pemaksa dan alat pengawas. Demikian juga dengan mantra Abal. Mantra Abal ini juga mempuyai fungsi di masyarakat penggunanya seperti yang dikemukakan oleh Bascom. Fungsi inilah yang membuat mantra masih tetap lestari walaupun sudah sangat kritis di tengah hampir punahnya bahasa Abal. Sementara sastra lisan yang lain, seperti pribahasa dalam bahasa Abal sudah tidak ditemukan lagi. Adapun fungsi mantra dalam masyarakat Abal adalah sebagai berikut.

1) Mantra dapat berfugsi sebagai sistem proyeksi, yaitu pencerminan angan-angan suatu kolektif.

Fungsi pertama ini hampir terdapat dalam setiap jenis mantra, baik itu mantra yang yang berfungsi individual seperti pada mantra bapupur yang bertujuan agar menjadi lebih cantik, maupun mantra yang bersifat sosial seperti mantra untuk menarik simpati orang dan menundukkan orang, dan juga mantra yang berfungsi untuk mengobati dan proyeksi dari mara bahaya, seperti mantra Sanggasangga.

\section{2) Mantra merupakan alat pengesahan} pranata-pranata dalam lembaga kebudayaan.

Dalam mantra Abal ini, paling tidak ada dua hal yang terlihat erat kaitannya dengan kepercayaan, yaitu: (1) adanya kekuatan magis yang mempunyai kekuatan secara halus berfungsi; dan (2) kekuatan keyakinan agama yang menunjukkan keyakinan suku Abal sebagai pemeluk Islam. Dari sini dapat disimpulkan juga bahwa mantra Abal ini menjadi pengesahan pranata Agama, yaitu Agama Islam dalam masyarakat Abal.

\section{3) Mantra merupakan sarana pendidikan.}

Sarana pendidikan di sini terutama dalam pendidikan agama, karena hampir semua mantra Abal berkaitan dengan Agama dengan mantra yang diakhir La ilaha illallah Muhammadar Rasulullah (yang harus dipahami makna dari kalimat zikir ini), pemakaian simbol-simbol keagamaan seperti Kata Yusuf yang merupakan simbol dari ketampanan seorang Nabi pada zaman Bani Israil. Orang yang 
menggunakan mantra ini harus orang yang bersih hati dan jiwanya serta dikenal sebagai orang yang taat dalam agama. Selain itu juga memahami tentang simbol-simbol keagamaan yang ada di dalam mantra tersebut. Hal ini menunjukkan bahwa mantra dalam masyarakat Abal hanya sebagai jalan untuk mencapai tujuan, dengan tetap mengharapkan dan tawakkal kepada Allah

\section{4) Mantra merupakan alat pemaksa dan alat pengawas.}

Mantra Sebagai sebuah sastra lisan bentuk puisi yang bersifat magis, biasanya menjadi alat pengawasi dan pemaksa secara halus, bukan secara fisik.

Mantra Abal sebagai salah satu bentuk kesustraan lama sekaligus sebagai warisan kebudayaan lama sudah semakin jarang dikuasai oleh masyarakat Abal kecuali orang tertentu. Hal ini menunjukkan kepada dua hal; pertama adanya masyarakat Abal yang masih meyakini kekuatan mantra di tengah masyarakat modern sekarang. Yang kedua; adanya masyarakat yang sudah berpaling dari kesusasteraan lama seperti mantra, sehingga tidak mengetahui lagi dan bahkan tidak meyakini lagi keampuhan dan kemagisan dari mantra. Hal ini juga yang membuat Suku Abal, Bahasa Abal, dan Sastra Abal akan punah, karena ditinggalkan pemiliknya.

\section{PENUTUP}

\subsection{Simpulan}

Mantra Abal yang ditemukan ada 11 mantra. Tujuh mantra menggunakan bahasa tunggal, tiga mantra menggunakan bahasa campuran, dan satu mantra menggunakan asing yaitu bahasa Arab. Tiga mantra yang menggunakan bahasa campuran menggunakan kalimat zikir dalam bahasa Arab untuk menutup mantranya. Mantra Abal yang ditemukan sangat dipengaruhi oleh agama Islam. Hal ini terjadi karena mayoritas masyarakat Abal. Hal ini menyebabkan mantra yang digunakan dan diayakini mengandung unsur kemagisan ini sangat dipengaruhi agama Islam. Selain itu, mantra-mantra Abal ini juga dipengaruhi unsur-unsur budaya yang merupakan warisan dari leluhur.

Dari sebelas mantra Abal ini ternyata yang paling banyak adalah yang berhubungan dengan cinta kasih yaitu sebanyak 6 mantra, sedangkan lima mantra yang lain terbagi ke tiga jenis lainnya, yaitu, pengobatan dua mantra, perisai diri dua mantra, dan satu mantra yang berhubungan dengan kecantikan.

Adapun secara struktur, semua mantra Abal ini mempunyai unsur judul semua. Adapun unsur pembuka hanya tidak dimiliki oleh satu mantra saja, yaitu mantra untuk mengobati sakit pinggang, sedangkan mantra yang lain semuanya memiliki unsur pembuka. Sedangkan Unsur Sugesti hampir dimiliki oleh semua mantra Abal ini kecuali mantra sagan mangatahui orang itu mau atawa kada lawan kita dan mantra maampihi urang karindangan. Kedua sugesti mantra ini tersimbol secara tersirat dalam unsur tujuan. Demikian juga dengan unsur tujuan/unsur penutup hampir dimiliki semua mantra Abal kecuali mantra Menundukkan Kekasih Lewat Suara dan Mantra untuk mengobati sakit pinggang.

Mantra Abal yang ditemukan ini hampir semuanya berbentuk puisi bebas yang terdiri dari beberapa kalimat, kecuali pada mantra untuk mengobati sakit pinggang. Dari 11 mantra yang diteliti tidak ditemukan ada mantra yang berbentuk syair, pantun, ataupun prosa liris.

Mantra Abal ini juga mempuyai fungsi di masyarakat penggunanya seperti yang dikemukakan oleh Bascom. mengemukakan empat fungsi mantra, yaitu Mantra dapat berfugsi sebagai sistem proyeksi, yaitu pencerminan angan-angan suatu kolektif; Mantra merupakan alat pengesahan pranata-pranata dalam lembaga kebudayaan; Mantra merupakan sarana pendidikan; Mantra merupakan alat pemaksa dan alat pengawas. Fungsi inilah yang membuat mantra masih tetap lestari walaupun sudah sangat kritis di tengah hampir punahnya bahasa Abal. Sementara sastra lisan yang lain, seperti pribahasa dalam bahasa Abal sudah tidak ditemukan lagi.

Mantra Abal sebagai salah satu bentuk kesustraan lama sekaligus sebagai warisan kebudayaan lama sudah semakin jarang dikuasai oleh masyarakat Abal kecuali orang tertentu. Hal ini menunjukkan kepada dua hal; pertama adanya masyarakat Abal yang masih meyakini 
kekuatan mantra di tengah masyarakat modern sekarang. Yang kedua; adanya masyarakat yang sudah berpaling dari kesusasteraan lama seperti mantra, sehingga tidak mengetahui lagi dan bahkan tidak meyakini lagi keampuhan dan kemagisan dari mantra. Hal ini juga yang membuat Suku Abal, Bahasa Abal, dan Sastra Abal akan punah, karena ditinggalkan pemiliknya.

\section{DAFTAR PUSTAKA}

Aminuddin. 2004. Pengantar Apresiasi Karya Sastra. Bandung: Sinar Baru Algesindo.

Anwar, D. 2005. Kamus Lengkap Bahasa Indonesia. Surabaya: Amelia.

Burchett, Patton E. 2008. The 'Magical' Language of Mantra. Journal of the American Academy of Religion. Volume: 76, Issue: 4, Pages 807-843.

Danadjaya, James. 2002. Folklor Indonesia: Ilmu Gosip, Dongeng, dan Lain-Lain. Jakarta: Grafiti.

Djamaris, Edwar, dkk. 1996. Nilai Budaya dalam Beberapa Karya Sastra Nusantara: Sastra Daerah di Kalimantan. Jakarta: Pusat Pembinaan dan Pengembangan Bahasa, Departemen Pendidikan dan Kebudayaan.

Endraswara, Suwardi. 2008. Metodologi penelitian Sastra (Epistemologi, Model, Teori dan Aplikasi). Yogyakarta: FBS Universitas Negeri Yogyakarta.

Furchan, Arief. 1982. Pengantar Penelitian dalam Pendidikan. Surabaya: Usaha Nasional.

Hamid, Ismali. DR. 1989. Kesusateraan Indonesia Lama Bercorak Islam. Jakarta: Radar Jaya Offset

Daod, Harun. 2010. Oral Traditions In Malaysia: A Discussion Of Shamanism. Jurnal Wacana. Vol. 12. No. 1 HIm $181-200$.

Hehahia, P.L., dan Farlin, S. (2008). Kamus praktis bahasa Indonesia. Jakarta: Scientific Press.

Hidayatullah. Dede. 2009. "Jenis dan Fungsi Mantra dalam Masyarakat Banjar," dalam Bunga Rampai Sastra Hasil Penelitian. Banjar Baru: Balai Bahasa provinsi Kalimantan Selatan.

2014. "Struktur dan Bentuk Mantra Banjar" Makalah. Tidak Diterbitkan. Banjarbaru: Balai Bahasa Kalimantan Selatan.

Jahdiah. 2013. "Penelitian Kosakata Dayak Abal" Laporan. Tidak Diterbitkan. Banjarbaru: Balai Bahasa Kalimantan Selatan.

Kasmilawati, Isna, Rustam Effendi. 2012. "Struktur Dan Fungsi Mantra Masyarakat Dayak Deah Desa Pangelak Kecamatan Upau Kabupaten Tabalong,” dalam Jurnal Bahasa Dan Sastra. 126-138.

Koentjaraningrat. 1986. Pengantar Ilmu Antropologi, Jakarta: AksaraBaru.

Kosasih. 2012. Dasar-Dasar Keterampilan Bersastra. Bandung: Yrama Widya. 
Dede Hidayatullah: Struktur, Bentuk dan Fungsi Mantra Abal

2003. Ketatabahasaan dan kesusastraan: Cermat Berbahasa Indonesia. Bandung: Yrama Widya.

Maknuna, dkk. 2013. "Mantra dalam Tradisi Pemanggil Hujan di Situbondo: Kajian Struktur, Formula, dan Fungsi," dalam Jurnal Publika Budaya. Vol. 1 No. 1 hlm. 1-15. Jember: Universitas Jember.

Pudentia, Dr. 2012. "Penglolaan Tradisi Lisan: Paradigma dan Pengembangan Program.” Makalah. Disampaikan pada Pelatihan Sastra Lisan, 22 April 2012 di Hotel Park Jakarta.

Rohim, Khairur dan Rustam Effendi. 2014. "Nilai Budaya dalam Mantra Banjar," dalam Jurnal Bahasa dan Sastra hlm 204-214.

Saputra, Heru Setya Puji. 2007. Memuja Mantra: Sabuk Mangir dan Jaran Goyang Masyarakat Suku Using Banyuwangi. Yogyakarta: LkiS

Siswantoro. 2011. Metode Penelitian Sastra. Yogyakarta: Pustaka Pelajar.

Sunarti, dkk. 1978. Sastra Lisan Banjar. Jakarta: Pusat Pembinaan dan Pengembangan Bahasa

Suwatno, Edi. 2012. "Bentuk dan Isi Mantra," dalam Jurnal Humaniora. Vol. 16, No. 3. hlm. 320 -331. Yogyakarta: Fak. Ilmu Budaya UGM.

Tim Penyusun. 2005. Mantra Banjar. Banjarbaru: Balai Bahasa Banjarmasin.

Wellek, Rene \& Austin Warren. 1995. Teori Kesusastraan. Terjemahan Mulianti Budiarti. Jakarta: PT Gramedia.

Zulfahnur, Z.F. 1999. Sejarah Sastra Indonesia. Jakarta: Departemen Pendidikan dan Kebudayaan. 